\title{
CONCEPTS
}

\section{The Use of Extrication Devices in Crevasse Accidents: Official Statement of the International Commission for Mountain Emergency Medicine and the Terrestrial Rescue Commission of the International Commission for Alpine Rescue Intended for Physicians, Paramedics, and Mountain Rescuers}

\author{
Eveline Winterberger, MD; Hans Jacomet, MD; Ken Zafren, MD; Grégoire Zen Ruffinen, MD; Bruno Jelk \\ From the International Commission for Mountain Emergency Medicine, Medical Commission of Alpine Rescue Switzerland (Dr \\ Winterberger), Swiss Air Rescue (Dr Jocomet), Rega Center, Zurich-Airport, Switzerland; Alaska Mountain Rescue Group, International \\ Commission for Mountain Emergency Medicine, Anchorage, AK, USA (Dr Zafren); International Commission for Mountain Emergency \\ Medicine, Medical Commission of the Valais Rescue Organisation, Swiss Air Rescue, Airport, Sion, Switzerland (Dr Ruffinen); and the \\ Technical Commission of the Valais Rescue Organisation and the Terrestrial Rescue Commission of the International Commission of Alpine \\ Rescue, Rescue Centre Zermatt, Zermatt, Switzerland (Mr Jelk).
}

\begin{abstract}
Injured patients in crevasses who are suspected of having sustained spinal injuries should ideally be extricated after being immobilized in a horizontal position on a stretcher and having a cervical collar applied. Sometimes, however, horizontal stabilization is not possible, because the crevasse is too narrow, and the patient needs to be stabilized in a vertical position. In such cases an extrication device can be a useful adjunct. The Kendrick Extrication Device ${ }^{\text {TWI }}$ stabilizes the position of the body and maintains firm support of the head, neck, and torso. Therefore, the International Commission for Mountain Emergency Medicine supports the use of this device in narrow crevasses, if horizontal evacuation is not possible.
\end{abstract}

Key words: emergency medicine, extrication device, crevasse accidents, mountain rescue, spinal injuries, KED, Kendrick Extrication Device

\section{Introduction}

Glacial sports continue to be a popular form of wilderness activity. A wide spectrum of injuries is associated with glacial accidents. They range from common extremity injuries, such as fractures, joint instability, or frostbite, to potentially life-threatening trauma. ${ }^{1}$

Corresponding author: Dr Eveline Winterberger, Rega Center, PO Box 1414, CH-8058 Zurich-Airport, Switzerland (e-mail: eveline. winterberger@rega.ch).

This article reflects the consensus of opinion of the International Commission for Mountain Emergency Medicine and the Terrestrial Rescue Commission of the International Commission for Alpine Rescue, which take full responsibility for the content.

This statement was not supported financially or materially by any producer of extrication devices. The authors are not involved in any related financial interest and did not get any grants or patents concerning the described devices.
Injured patients in crevasses who are suspected of having sustained spinal injuries should ideally be extricated after being immobilized in a horizontal position on a stretcher and having a cervical collar applied. ${ }^{2}$ However, sometimes this kind of rescue and evacuation is not possible because the crevasse is too narrow. The Kendrick Extrication Device (FERNO KED ${ }^{\circledR}$, Troisdorf, Germany), due to its rigidity, stabilizes the position of the body and maintains firm support of the head, neck and torso. ${ }^{3}$ This device is most commonly used after motor vehicle crashes, but it can also be used to advantage in difficult terrain, especially when there is a lack of space in a narrow crevasse. Swiss mountain rescuers have successfully used this device in the field, especially in glacier accidents in which patients have been injured in narrow crevasses, as shown in Figure 1. These anecdotal reports and the potential benefits of using the 


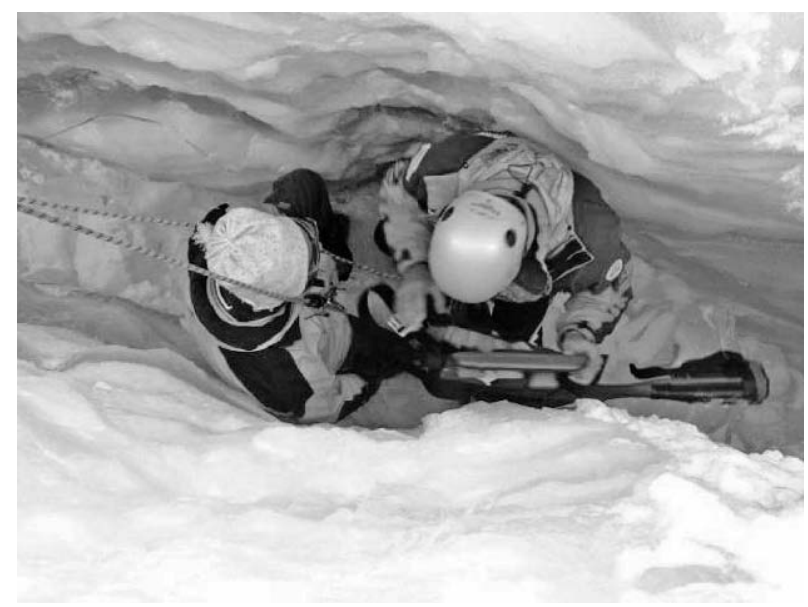

Figure 1. Patient in a narrow crevasse being secured using a safety harness.

extrication device in crevasse accidents have been extensively discussed within the International Commission for Mountain Emergency Medicine (ICAR MEDCOM), which developed the following statement, based on a consensus of expert opinion.

\section{Recommendation}

In the case of an injured patient who is suspected of having sustained spinal injuries, when a stretcher cannot be used because the crevasse is too narrow, the Medical Commission of the ICAR supports the use of a KED. The evacuation of the patient should be carried out by taking the following steps: (1) The patient with a suspected back injury is placed in a cervical collar then stabilized in the device (Figure 2). (2) The patient should be lifted using a supplement safety harness (eg, Petzl Navaho ${ }^{\circledR}$, Crolles, France ${ }^{4}$ ) and not directly by the straps attached to the device (Figure 3). (3) If a vertical raise is essential, the use of a supplement suspension line at the top of the extrication device may reduce the pressure on the axial skeleton. This should be attached to the main line with an adjustable system (eg, ascender or Prusik) (Figure 3). However, be aware that every change of position should be done as gently as possible, especially if shock and hypothermia are present. ${ }^{5,6}$ (4) After extrication, the patient should be moved from a sitting to a horizontal position as soon as possible.

\section{Acknowledgments}

This statement has been discussed and officially approved at the 2005 ICAR MEDCOM meetings in Paklenica, Croatia, and Cortina d' Ampezzo, Italy, by the following members of the ICAR MEDCOM in addition

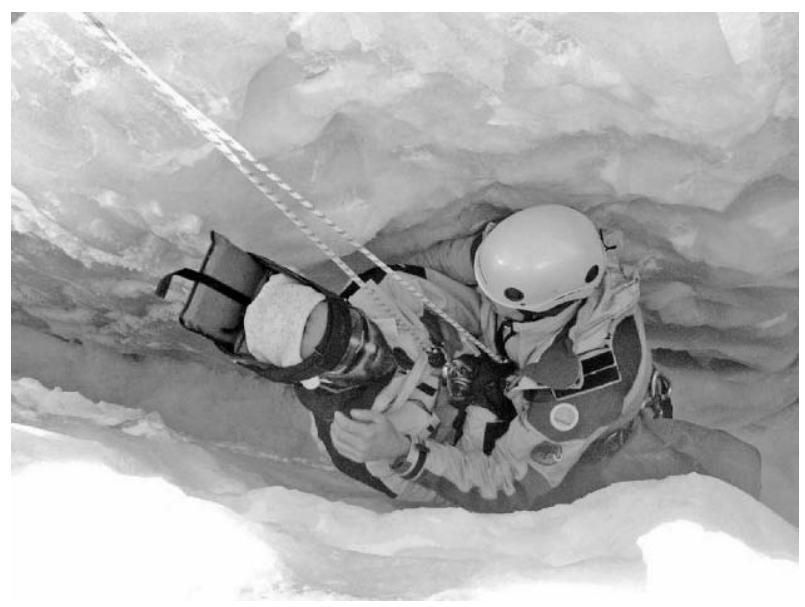

Figure 2. Applying cervical collar and extrication device in the crevasse.

to the authors: Hermann Brugger (President, Italy), Giancelso Agazzi (Italy), Borislav Aleraj (Croatia), Jeff Boyd (Canada), Ramon Chiocconi (Argentina), Tore Dahlberg (Norway), John Ellerton (England), Fidel Elsensohn (Austria), Silvia Ferrandis (Spain), Herbert Forster (Germany), Xavier Ledoux (France), Peter Paal (It-

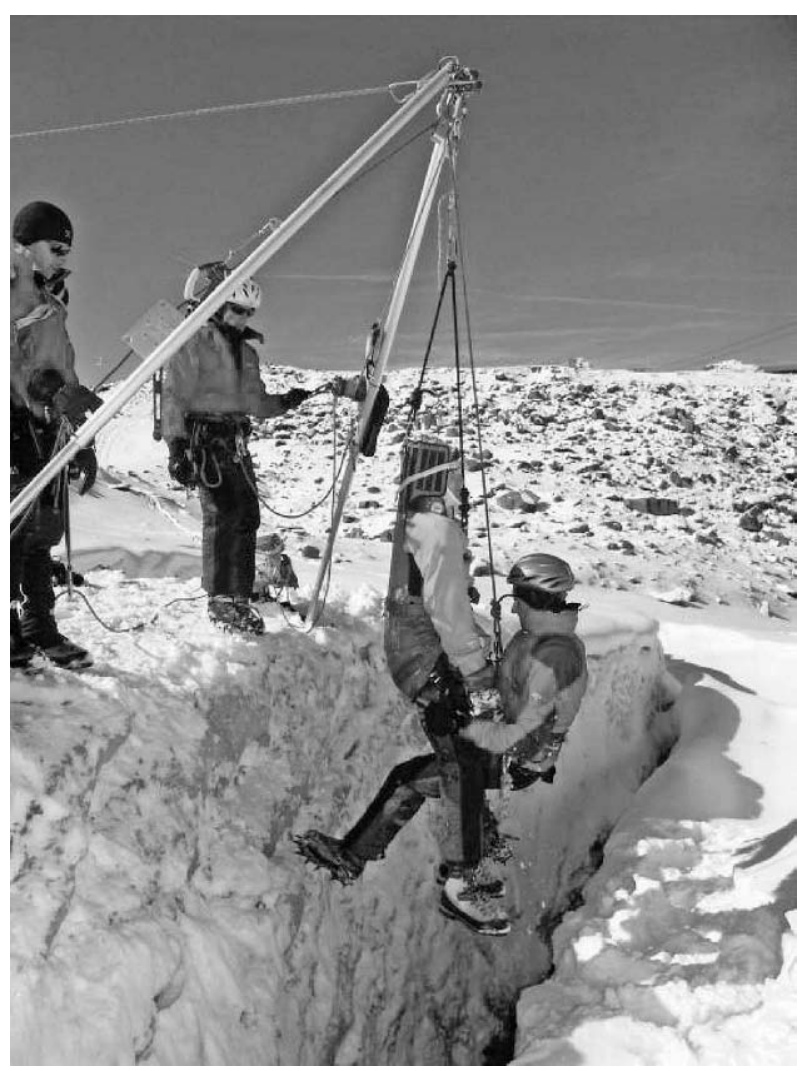

Figure 3. Patient and rescuer at the edge of the crevasse. The patient is lifted using a supplemental safety harness. 
aly), Günther Sumann (Austria), Dario Svajda (Croatia), Iztok Tomazin (Slovenia), Igor Zulian (Croatia).

\section{References}

1. Schindera ST, Triller J, Steinbach LS, Zimmermann H, Takala J, Anderson SE. Spectrum of injuries from glacial sports. Wilderness Environ Med. 2005;16:33-37.

2. De Lorenzo RA. A review of spinal immobilization techniques. J Emerg Med. 1996;14:603-613.
3. Howell JM, Burrow R, Dumontier C, Hillyard A. A practical radiographic comparison of short board technique and Kendrick Extrication Device. Ann Emerg Med. 1989;18: 943-946.

4. Petzl Official Website. Available at: http://en.petzl.com/ petzl/Accueil. Accessed August 19, 2007.

5. Larach MG. Accidental hypothermia. Lancet. 1995;345: 493-498.

6. Durrer B, Brugger H, Syme D. The medical on-site treatment of hypothermia. High Alt Med Biol. 2003;4:99-103. 